CIRJE-F-356

The MDGs and Exit Time: The Case of the Philippines

\author{
Yasuyuki Sawada \\ University of Tokyo \\ Jonna P. Estudillo \\ University of the Philippines
}

August 2005

CIRJE Discussion Papers can be downloaded without charge from:

http://www.e.u-tokyo.ac.jp/cirje/research/03research02dp.html

Discussion Papers are a series of manuscripts in their draft form. They are not intended for circulation or distribution except as indicated by the author. For that reason Discussion Papers may not be reproduced or distributed without the written consent of the author. 


\title{
The MDGs and Exit Time: The Case of the Philippines
}

\author{
by \\ Yasuyuki Sawada* \\ Faculty of Economics, University of Tokyo, \\ Tokyo 113-0033, Japan \\ and \\ Jonna P. Estudillo \\ School of Economics, University of the Philippines, \\ Diliman, Quezon City 1101, \\ Philippines
}

\begin{abstract}
This paper evaluates whether the Philippines will be able to halve the incidence of poverty between 1990 and 2015. Using the concept of exit time and household-level data, we found that the Philippines will be unlikely to do so.
\end{abstract}

Keywords: Poverty; Exit time; MDGs

JEL Classifications: I32; O53.

* Corresponding author. Phone: +81-3-5841-5572; Fax:+81-3-5841-5521; Email: sawada@e.utokyo.ac.jp

Acknowledgments: The National Statistics Office, the National Statistical Coordination Board, the Department of Agrarian Reform, and the Department of Education supplied the necessary data. We would like to thank Shaohua Chen for her technical assistance and the World Bank and Asian Development Bank for relevant information on current government programs on poverty reduction. The usual disclaimer applies. 


\section{Introduction}

The international development objectives have converged to reduce poverty in the world since the signing of the Millennium Declaration in September 2000 (United Nations, 2000). The Millennium Development Goals (MDGs) is a concise set of goals, numerical targets and quantifiable indicators to assess the progress of poverty reduction in the whole world specified in the Millennium Declaration. In the Philippines, poverty reduction has been a top priority of its government since $1986 .{ }^{1}$ This study aims to assess the progress of the Philippines in reducing poverty using the MDGs as the benchmark. Our analysis focuses on the assessment of progress with respect to Goal 1, i.e., eradicate extreme poverty and hunger and, more specifically, Target 1, i.e., to halve the proportion of people living on less than a dollar a day between 1990 and 2015.

While Besley and Burgess (2003) used cross-country data to evaluate the progress on Target 1 at the global level, no previous attempts have been done to evaluate the progress of poverty reduction in the Philippines using Target 1 as a standard. We incorporated the interprovincial price variations in the US $\$ 1.08$ poverty line because such price differences can be considerable in a large and poorly integrated economy such as the Philippines. First, we estimate the internationally comparable poverty line for the each province by using the provincial-level price information. Second, by applying the concept of exit time developed by Kanbur (1987) and Morduch (1998) to the household-level data from the Family Income and Expenditure Surveys (FIES), we made a quantitative assessment of whether the Philippines can achieve Target 1.

\footnotetext{
${ }^{1}$ The Aquino administration (1986-92) had the Comprehensive Agrarian Reform Program as the centerpiece of its anti-poverty program; the Social Reform Agenda for the Ramos administration (1992-98); the "Lingap Para sa Mahirap" (looking after the poor) for the Estrada administration (1998-2001); and the "Kapit-bisig Laban sa Kahirapan" (linking arms against poverty) for the Arroyo (2001- ) administration.
} 


\section{Provincial poverty line}

The domestic poverty line constructed by the National Statistical Coordination Board (NSCB) of the Philippine government was the most commonly used poverty line. Target 1 , on the other hand, was set on the international poverty line, which was pegged at US\$1.08 per capita per day. The use of the consumption-based purchasing power parity (PPP) exchange rate has been generally acceptable to convert the US $\$ 1.08$ poverty line into its local currency equivalent (Chen and Ravallion, 2004). We believe, however, that the PPP has to be adjusted to incorporate interprovincial price variations in order to make a more accurate assessment of the provincial poverty situations. Thus, we constructed a provincial-specific PPP adjusted for interprovincial price variations. The PPP for province $j$ in the Philippines in year $t$ is defined as

$$
\frac{P_{j, t}^{P h}}{P_{1993}^{U S}},
$$

where $P_{j, t}^{P h}$ is the overall price level in province $j$ and $P_{1993}{ }^{U S}$ is the aggregate price level in the US in the benchmark year, 1993. The provincial PPP in Eq. (1) can be represented as a product of the ratio of the provincial-specific price level to the national price level (term A), consumer price index (CPI) in the Philippines (term B), and the country-level PPP in 1993 (term C)

$$
\underbrace{\frac{P_{j, t}^{P h}}{P_{1993}^{U S}}}_{\begin{array}{c}
\text { Provincial } \\
\text { PPP }
\end{array}}=\underbrace{\frac{P_{j, t}^{P h}}{P_{t}^{P h}}}_{\begin{array}{c}
\text { A } A) \\
\text { Relative } \\
\text { price } \\
\text { (Term A) }
\end{array}} \times \underbrace{\frac{P_{t}^{P h}}{P_{1993}^{P h}}}_{\begin{array}{c}
\text { B) } \\
\text { CPI in } \\
\text { the Philippines } \\
\text { (Term B) }
\end{array}} \times \underbrace{\frac{P_{1993}^{P h}}{P_{1993}^{U S}}}_{\begin{array}{c}
\text { (C) } \\
\text { Benchmark } \\
\text { PPP } \\
(\text { Term } C)
\end{array}},
$$


where $P_{t}^{P h}$ is the overall price level in the Philippines. ${ }^{2}$ We computed the provincial relative price (term A) in Eq. (2) using a two-step procedure. In the first stage, we utilized the detailed provincial-level individual commodity prices collected by the National Statistics Office (NSO) to calculate the benchmark relative prices for each province. More specifically, for each province, we collected the 2003 price information on rice as a major staple, poultry meat as source of protein, and electricity as a non-food expenditure item, to construct the benchmark price. In the second stage, we utilized the provincial- and national-level CPI to compute the relative prices for other years.

Term B in Eq. (2) was computed using the CPI from the International Financial Statistics of the International Monetary Fund. The benchmark PPP in term C was simply the 1993 consumption-based PPP taken from the Penn World Tables 5.7. Note that this is also the benchmark PPP used by Chen and Ravallion (2004). The monthly value of the US $\$ 1.08$ per capita per day corresponds to the provincial PPP in Eq. (2) multiplied by 32.74 .

We compared our provincial poverty lines with the domestic provincial poverty lines calculated by the NSCB and with the poverty lines based on the real expenditure calculated by Balisacan (2003). ${ }^{3}$ A simple OLS regression of our poverty line with that of the NSCB showed a slope of 0.56 and, in the case of Balisacan (2003), a slope of 0.17 . Thus, our poverty line appears to have reasonably captured the interprovincial price variations.

We did our calculations on the provincial incidence of poverty using the expenditure data from the FIES in 1985, 1988, 1991, 1994, 1997, and 2000. ${ }^{4}$ In accordance to Target 1, our poverty incidence is at the level of individual members of the households. Table 1 shows an overall reduction in poverty from 1985 to 2000 . Such reduction was particularly remarkable in

\footnotetext{
${ }^{2} \mathrm{~A}$ more detailed estimation procedure can be found in Sawada and Estudillo (2005).

${ }^{3}$ The NSCB domestic poverty lines were calculated using the prevailing domestic prices of a basket of commodities a typical poor consumed. Balisacan's (2003) poverty line was calculated by deflating the nominal expenditure by the true cost of living index, which is defined for fixed reference prices and reference household characteristics.

${ }^{4}$ Estimates of the national and provincial US $\$ 1.08$ per capita per day poverty lines and the corresponding poverty incidence indicators are available from the authors upon request.
} 
provinces with higher initial levels of poverty in 1985 such as those located in Bicol Region (e.g., Albay, Catanduanes, and Sorsogon), Eastern Visayas (e.g., Siquijor, Leyte, Southern Samar, Southern Leyte, and Western Samar), and Northern Mindanao (e.g., Misamis Occidental and Misamis Oriental). Provinces with lower incidence of poverty from 1985 were those located closer to Manila such as provinces in the Southern Tagalog Region in the CALABARZON area (e.g., Laguna, Rizal, Batangas and Cavite) and Central Luzon Region (e.g., Bulacan, Bataan, Pampanga, and Nueva Ecija). Moreover, these provinces experienced higher growth rates of household income as industries tended to be set up in these provinces because of its proximity to Manila, better communication and telecommunication facilities, and relatively more educated labor force.

\section{The role of economic growth in achieving the Target 1}

Using the PPP-based provincial poverty line, we applied the concept of exit time developed by Kanbur (1987) and Morduch (1998) to quantify the income growth rate necessary to achieve Target 1 . Exit time, $t_{i}$, is defined as the time an individual $i$ with expenditure $y_{i}$ below the poverty line, $z$, will exit the poverty situation,

$$
t_{i}=\frac{\ln (z)-\ln \left(y_{i}\right)}{\ln (1+g)}
$$

where $g$ is the growth rate of real per capita expenditure of individual $i$.

Let $\mu_{t}^{p}$ represents the median real per capita expenditure of an individual poor in province $p$ in year $t$ and $t_{\mu}^{p}$ represent the exit time of the median poor individual. Since the MDGs require $t_{\mu}^{p}$ to be equal to 25 years, i.e., from 1990 to 2015 , we can easily compute the required real per capita expenditure growth rate of the median poor, $g^{p}$. Since the FIES is not available in 1990, 
we utilized the data on 16,971 households in the 1988 FIES to quantify the growth that is necessary to halve the incidence of poverty between 1988 and 2015 . The necessary growth rate of real per capita expenditure is represented by

$$
g^{p}=\exp \left[\frac{\ln (z)-\ln \left(\mu_{1988}^{p}\right)}{27}\right]-1
$$

This can be considered as a lower bound of the necessary growth rate of real per capita expenditure to achieve Target 1 between 1990 and 2015.

The required growth rate for each province varies from the lowest of $0.14 \%$ per year (in Cavite) to the highest of $1.75 \%$ per year (in Romblon). ${ }^{5}$ According to Table 1, the Philippines as a whole will not be able to comply with Target 1 as the real per capita expenditure growth rate of the median poor is only $0.23 \%$ per annum. The real per capita expenditure of the median poor needs to grow by an additional $0.55 \%$ point per annum in order to comply. Out of the 72 provinces, only 15 (of which 10 are well within reach from Manila) will be able to comply with Target $1 .^{6}$

Figure 2 shows the kernel density distributions of provincial-level actual real per capita expenditure growth rate and the required growth rate to achieve Target 1. A mere eye-ball test of the first-order stochastic dominance shows that the distribution of the actual growth rate was dominated by the distribution of the required growth rate. Indeed, the two-sample KolmogorovSmirnov test rejected overwhelmingly the hypothesis on equality of these two distribution functions; the KS test statistic for equality of these CDFs is 0.500 with a P value less than 0.01 . Figure 2 is a kernel density function of the growth rate gap, which is defined as the difference between the necessary growth rate to achieve Target 1 and the actual growth rate. It is interesting

\footnotetext{
${ }^{5}$ The provincial-wise necessary growth rates are available from the authors upon request. ${ }^{6} \mathrm{We}$ eliminated six provinces because these provinces were not yet established in 1988 or were not represented in the FIES.
} 
to find a symmetric distribution but obviously a majority of the provinces took a negative value. Hence, we may conclude that, at the national level, the Philippines will not be able to achieve Target 1. It is important to mention that Chen and Ravallion (2004) and Besley and Burgess (2003) assessed that East Asia as a whole will be most likely to comply with Target 1 so that the Philippines appears to be an exception.

\section{Conclusions}

This paper aimed to assess the performance of the Philippines with respect to Target 1 using the US\$1.08 per capita per day poverty line adjusted for interprovincial price differences. Our evidences showed that the Philippines as a whole will not be able to comply with Target 1 , although 15 of its provinces will be able to do so. These provinces were closer to Manila, characterized by higher growth rates of individual per capita real expenditure, and had lower incidence of poverty in 1988. This suggests the importance of policy interventions that mitigate the emergence of regional disparity in achieving the MDGs. Balisacan and Fuwa (2003) suggested political competitiveness that may lead to income convergence across provinces. 


\section{References}

Balisacan, Arsenio M. (2003), "Poverty and inequality," in Arsenio Balisacan and Hall Hill eds., The Philippine Economy: Development, Policies, and Challenges, Ateneo de Manila University Press, Philippines.

Balisacan, Arsenio M. and Nobuhiko Fuwa (2003), "Growth, inequality and politics revisited: a developing-country case," Economics Letters 79 (1), 53-58.

Besley, Timothy and Robin Burgess (2003), "Halving global poverty," Journal of Economic Perspectives 17 (3), 3-22.

Chen, Shaohua and Martin Ravallion (2004), "How have the world's poorest fared since the early 1980s?” World Bank Research Observer 19 (2), 141-169.

Kanbur, Ravi (1987), “Measurement and alleviation of poverty,” IMF Staff Papers 34 (1), 60-85.

Morduch, Jonathan (1998), "Poverty, economic growth, and average exit time," Economics Letters 59, 385-390.

Sawada, Yasuyuki and Jonna P. Estudillo (2005), "Trade, migration, and poverty reduction in the globalizing economy: the case of the Philippines." Paper presented at the UNU-WIDER Conference "The Impact of Globalization on the Poor in Asia", 25-26 April 2005, Tokyo, Japan.

United Nations (2000), United Nations Millennium Declaration, Resolution 55/2 adopted by the General Assembly, United Nations. 


\section{Table 1}

International poverty lines and poverty incidence in the Philippines, 1985-2000

\begin{tabular}{|l|c|c|}
\hline Year & US\$1 per capita per day (Php annual values) & $\begin{array}{c}\text { Individual poverty } \\
\text { incidence (\%) }\end{array}$ \\
\hline & & 23 \\
\hline 1985 & 2003 & 24 \\
\hline 1988 & 2497 & 24 \\
\hline 1991 & 3452 & 17 \\
\hline 1994 & 4343 & 16 \\
\hline 2000 & 5413 & 18 \\
\hline [A] Required real growth rate of per capita expenditure (\%) & 0.79 \\
\hline [B] Actual real growth rate of per capita expenditure (\%) & 0.24 \\
\hline [A-B] Growth gap & 6614 & -0.55 \\
\hline
\end{tabular}


Figure 1

Distribution of actual and required growth rates of real per capita expenditure in the Philippines, 1988-2000

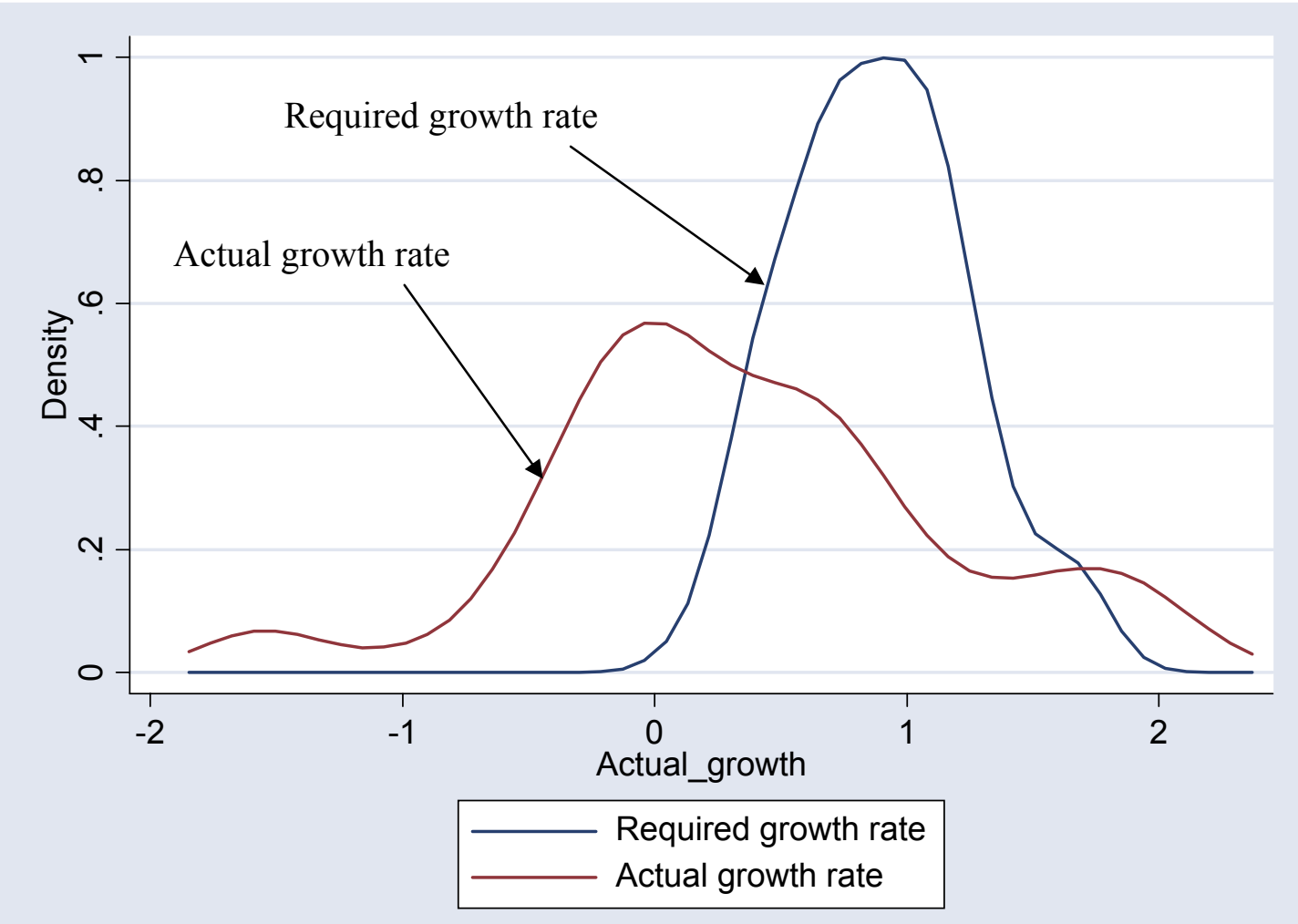


Figure 2

Distribution of the gap between the actual and the required growth of real per capita expenditure in the Philippines, 1988-2000

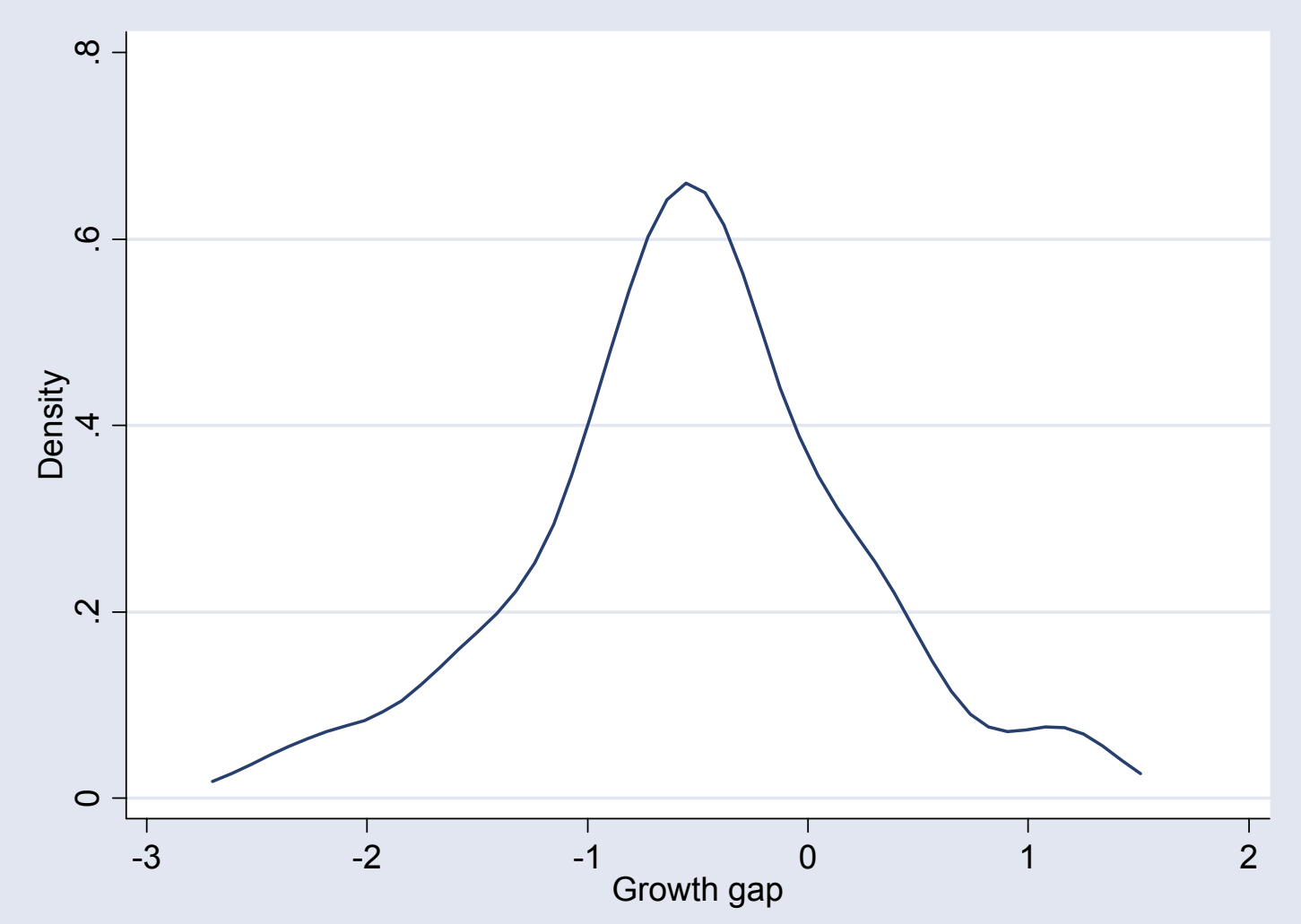

